\title{
Historiografía y capital simbólico de los estudios en Comunicación, Cine y Televisión en España
}

\section{Historiography and symbolic capital of Communication, Film and Television Studies in Spain}

\author{
Manuel Palacio; Ana Mejón
}

Cómo citar este artículo:

Palacio, Manuel; Mejón, Ana (2020). “Historiografía y capital simbólico de los estudios en Comunicación, Cine y Televisión en España”. Profesional de la información, v. 29, n. 4, e290442.

https://doi.org/10.3145/epi.2020.jul.42

Artículo recibido el 10-01-2020

Aceptación definitiva: 02-02-2020

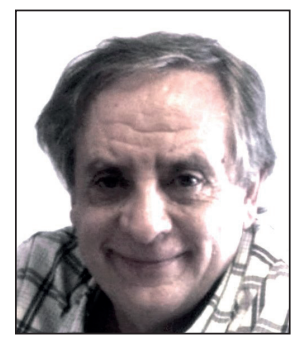

Manuel Palacio

https://orcid.org/0000-0003-0378-8860

Universidad Carlos III de Madrid

Departamento de Comunicación

Madrid, 133

28903 Getafe (Madrid), España

jpalacio@hum.uc3m.es

\section{Resumen}

Se abordan el posicionamiento actual de la investigación en Comunicación desde una perspectiva historiográfica y su legitimación a través de la creación de capital simbólico. La investigación se divide en tres partes. En la primera, se inspeccionan los orígenes de las disciplinas académicas de Comunicación a través de la creación de las primeras facultades de Ciencias de la Información y la incorporación de sus primeros profesores durante los años ochenta. En la segunda, se observa el surgimiento de las áreas de conocimiento en la década de los noventa, que establecen la actual división dentro de las disciplinas de las Ciencias de la Comunicación. Para finalizar, se analiza la creación de capital simbólico de la disciplina mediante los nombramientos de doctores honoris causa por parte de facultades de Ciencias de la Comunicación en España.

\section{Palabras clave}

Ciencias de la Comunicación; Investigación; Plan de estudios; Periodismo; Comunicación Audiovisual; Cine; Televisión; Publicidad; Honoris causa; Universidad; Áreas de conocimiento; Evaluación.

\begin{abstract}
The current positioning of research on Communication from a historiographic perspective and its legitimacy through the creation of symbolic capital are addressed. The research is divided into three parts: (1) the origins of the academic disciplines of Communication are inspected through the creation of the first faculties of Communication Sciences and the incorporation of their first professors; (2) the emergence of the areas of knowledge, which establish the current division within the disciplines of Communication Sciences, is observed; (3) the creation of symbolic capital related to the discipline is analyzed through the awarding of honorary doctorates (honoris causa) by the faculties of Communication Sciences in Spain.
\end{abstract}

\section{Keywords}

Communication Sciences; Research; Syllabus; Journalism; Audiovisual; Cinema; Television; Media studies; Advertising; Honorary doctorate; University; Areas of Knowledge; Evaluation.

Este trabajo es un resultado del proyecto I+D+i “Cine y televisión 1986-1995: modernidad y emergencia de la cultural global” (Ref. CSO2016-78354-P), Agencia Estatal de Investigación, Ministerio de Ciencia, Innovación y Universidades, Gobierno de España. 


\section{Introducción}

En los últimos años han proliferado en revistas y monografías trabajos sobre el estatuto de la investigación en Comunicación en España. Es muy posible que la amplia bibliografía haya creado un bloque de pensamiento consistente que posee tangibles potencialidades para que se asiente una reflexión colectiva disciplinar. Pueden mencionarse tres volúmenes: Investigar en la era neoliberal. Visiones sobre la investigación en Comunicación en España, editado por Rodríguez-Serrano y Gil-Soldevilla (2018); Epistemología de la Comunicación y cultura digital: retos emergentes, coordinado por Sierra-Caballero y Alberich-Pascual (2019), y Docencia e investigación en Comunicación en España, coordinado por Clemente-Mediavilla y Ramírez-Alvarado (2020). El primero, impulsado por Javier Marzal, uno de los académicos más activos en este tema, es un verdadero vademécum sobre esta problemática. Está editado en la colección Aldea Global, coparticipada por cuatro universidades con estudios de comunicación: Universitat Pompeu Fabra (UPF), Universitat de València (UV), Universitat Jaume I (UJI) y Universitat Autònoma de Barcelona (UAB); y en sus páginas escriben más de dos docenas de investigadores provenientes de una decena de universidades españolas. El segundo, editado por la editorial de la Universidad de Granada, recoge las intervenciones de otra docena de investigadores de más de diez universidades públicas y privadas. Por último, el tercero tiene la eventualidad de reunir la mirada retrospectiva de los decanos agrupados en la Asociación Española de Universidades con Titulaciones de Información y Comunicación (ATIC) hacia el origen de sus facultades.

Sin embargo, la amplia bibliografía también provoca una sensación de uniformidad y de insistencia en aspectos comunes, como:

- el campo de la Comunicación es probablemente el más vigoroso de las ciencias sociales;

- la cultura de la evaluación, impuesta por el neoliberalismo produce desajustes en las carreras universitarias;

- el aumento de lecturas de tesis y de la publicación en revistas de impacto augura un futuro con altibajos, pero esperanzador.

Los riesgos de las semejanzas han sido comentados con socarronería por Goyanes que, avisando de los peligros de la estandarización de las prácticas investigadoras, considera:

"la práctica de una investigación estándar plantea un modo de pensar y hacer ciencia basado en la convención de lo correcto colectivo, del 'no todos podemos estar equivocados'”' (Goyanes, 2017, p. 29).

Resulta, en suma, muy pertinente hacer algún tipo de balance que permita problematizar el estado de la investigación en Comunicación. Tal vez la primera proposición que hacemos es dejar de lado el subyacente 'ombliguismo' del que a veces pecamos los estudiosos en Comunicación. Porque mirar únicamente lo que nos ocurre a nosotros, para establecer desde allí la medida de las cosas, parece una actitud algo cateta. A poco que rasquemos la superficie, comprobamos que no somos los de Comunicación los que aglutinamos más estudiantes en el conjunto de los centros universitarios o que nuestros investigadores están lejos de ser los que más dinero consiguen para las arcas de las universidades. 0 incluso también sabemos que nuestra tasa de éxito en las evaluaciones compartidas con otras disciplinas es menor que las que consiguen 'otros' de las Ciencias Sociales. Son datos a tener en consideración. No siempre se cumple. Obsérvese, como ejemplo de lo dicho, una reciente carta que la asociación de decanos envió a la Aneca sobre los criterios de evaluación.

Con fecha 28 de mayo de 2019, la ATIC le planteó la necesidad de la creación de un nuevo campo de evaluación Cneai para la Comunicación, que engloba las áreas de conocimiento de Comunicación Audiovisual y Publicidad, y Periodismo, en virtud de la consolidación de nuestras investigaciones y estudios universitarios desde hace ya casi cincuenta años, y siendo necesaria la segregación del resto de las denominadas Ciencias Sociales debido a la relevancia adquirida de dichos estudios en la actual Sociedad de la Información y de la Comunicación.

Indirectamente, el 'ombliguismo' posee otro efecto, el de la estandarización del pensamiento de las áreas de Comunicación. Podría decirse algo como:

'no removamos mucho las aguas de nuestra bañera, no sea que se desborden con el movimiento y se viertan'.

Por eso llama la atención la omisión de cualquier comentario sobre la polaridad ideológica que existe en el campo. Nadie parece atender la posible incidencia que posee un pensamiento de izquierda o la persistencia de una veta de académicos eclesiásticos. Por supuesto que los puntos de vista diferenciados son la base de las sociedades democráticas, más aún en tiempos en los que la crispación política está a la orden del día. No obstante, sorprende la ausencia de especulaciones sobre el origen o las disparidades en el campo de la comunicación.

En realidad, el problema es que no hay ningún acuerdo contemporáneo sobre qué es eso que llamamos "Comunicación", y cómo podemos incidir desde el campo en la sociedad. Existen, claro está, unos grados que se imparten en las facultades de Ciencias de la Información / Ciencias de la Comunicación. Y también unas comisiones de Ciencias Sociales en los diversos niveles que constituyen la cultura de la evaluación que aceptan los trabajos de los que se autopresentan como "Comunicación". Pasamos de puntillas por el hecho de que el registro de las tesis doctorales o las aplicaciones de los planes nacionales, dos aspectos esenciales para la investigación, carecen de una categoría de 'Comunicación'. Y cada vez son más frecuentes los casos de compañeros que solicitan ser evaluados por la Cneai en mesas diferentes al campo 7 
(Ciencias Sociales) e incluso algunos que presentan sus currículos en la Aneca para las acreditaciones en ramas distintas que las que se establecen para el juicio de las Ciencias Sociales.

En este trabajo partimos de la obviedad, no siempre atendida, de que en el contexto histórico y social se encuentran buena parte de las respuestas no contestadas sobre cómo somos. Existe una periodización inútil de los estudios de Comunicación que, sin basarse en un análisis histórico, sorprendentemente ha sido repetida y citada en cascada desde hace dos décadas. Sin embargo, lo cierto es que nada de lo comentado anteriormente estaba prefijado ni cuando empezaron los estudios sobre comunicación en los primeros años setenta ni tampoco cuando comenzó la cultura de la evaluación en los noventa. Es decir, las cosas hubieran podido desarrollarse de otra manera. Al igual que en otras disciplinas, en los años setenta y ochenta se produjeron las disputas epistemológicas que fraguaron en las hegemonías contemporáneas. En otros campos, puede rememorarse el debate entre internacionalistas y autóctonos en económicas o las diferencias entre la filología y la literatura.

Hoy, establecer una historiografía de la investigación en la Comunicación es imprescindible. Con modestia queremos empezar ese trabajo. En primer lugar, abordaremos el nacimiento de las primeras facultades en la universidad española; luego trataremos la creación de las áreas de conocimiento con un comentario sobre la generación de los profesores "idóneos", así como sobre las primeras aplicaciones de la cultura de la evaluación universitaria. Finalmente, paralelo a este contexto de definición histórica del campo de la Comunicación, observaremos la manera en que las facultades de Ciencias de la Información/Comunicación han buscado crear capital simbólico en su disciplina en el conjunto de sus universidades a partir de las políticas de adjudicación de doctorados Honoris Causa.

\section{Los orígenes}

La Comunicación en España constituye hoy una disciplina académica y un campo de materias que, por comodidad (y ahorro económico), se agrupan en algunas de las comisiones de Ciencias Sociales en la cultura de la evaluación. Entre medias de unas y otras se encuentran las áreas de conocimiento, el lugar establecido oficialmente por las autoridades para la inclusión administrativa del profesorado funcionario. Pero todo ello no son singularidades que cayeron un día del cielo, sino que responden siempre a un determinado contexto histórico, social y a unas lógicas institucionales de la propia universidad.

La comunicación audiovisual y la publicidad han tenido desde siempre un difícil acomodo en el territorio de la Comunicación

Los orígenes del campo científico de lo que hoy día es "Comunicación" evidencia que se trata de una derivación de los estudios y disciplinas de los estudios de Periodismo. La Comunicación Audiovisual y la Publicidad han tenido desde siempre un difícil acomodo en ese territorio. Esta afirmación, que no pretende ser ninguna provocación, es el resultado de una simple mirada histórica. Fijémonos en los nombres, trascendiendo de un ramplón nominalismo. Los estudios de Comunicación (hipotéticamente) se podrían haber llamado Comunicación Social, como en muchos países de América Latina; Información y Comunicación, como en Francia; Ciencias de la Comunicación, como preconizaba en 1972 el sociólogo Vidal-Beneyto, o simplemente, Periodismo y medios de comunicación, como se pauta en la norma legal por la que se permite crear las facultades de Ciencias de la Información (Ley 14/1970). Desaparece en los títulos de las facultades toda mención a los medios de comunicación y se califican como Ciencias de la Información, que le da un sesgo menos profesional que el que tenía la denominación clásica de Escuela Oficial de Periodismo.

Huelga decir que un acercamiento a las primeras asignaturas universitarias que se propusieron permite identificar que, en origen, se buscaba casi exclusivamente dar formación de ciclo superior a los periodistas que acudían a escuelas especializadas. El estudio de los procesos comunicativos, tal y como se entendía en países de nuestro entorno, no estaba ni de lejos en la agenda de los que crearon nuestras facultades. Todo ello se observa en el Decreto 2070/1971, inicial regulación de los estudios de Comunicación en España, que establece en su Artículo primero:

"Las universidades que deseen incorporar a la educación de este nivel los estudios de periodismo y demás medios de comunicación social, podrán solicitar del Ministerio de Educación y Ciencia, para su tramitación correspondiente, la creación de Facultades de Ciencias de la Información" (España, 1971, Art. 1).

Asimismo, esta norma contemplaba las enseñanzas de periodismo, cinematografía, televisión, radiodifusión y publicidad por parte de las nuevas facultades, cuya creación fue solicitada en primera instancia en el año 1972 por la Universidad Complutense de Madrid (UCM) y la Universitat Autònoma de Barcelona (UAB). En Madrid se implementaría la carrera con las ramas de Periodismo, Ciencias de la imagen visual y auditiva y Publicidad, y en Barcelona únicamente Periodismo. El hecho, visto hoy, parece anecdótico, pero no lo es. En Barcelona, al margen de otros aspectos de enorme calado, la visión del periodismo debe ser más amplia y va fraguando la semilla de la Comunicación como campo propio y disciplina en la que se atienden los procesos de los medios. Es el punto a recordar que, en una fecha tan inicial como 1982 , una delegación de profesores de la UAB asiste al congreso de la AIERI/IAMCR con el fin de presentar la candidatura de Barcelona para el congreso de la célebre Asociación Internacional de Comunicación $(A / C)$ en el año 1988. Y esa delegación estuvo formada por dos profesores de Periodismo (Miquel de Moragas y Manuel Pares) y dos de Comunicación Audiovisual (Armand Balsebre y Emili Prado). 
Por su parte, los primeros planes de estudios -objeto de numerosos cambios en aquellos años- establecen el inicial mapa cognitivo de lo que luego podríamos denominar el inicial campo de las licenciaturas de Comunicación. La tabla 1 recoge la propuesta que en 1974 la Dirección General de Universidades aprobó como guía. En ella se observa un claro predominio de disciplinas humanistas en detrimento de aquellas que provienen de las Ciencias Sociales. En este sentido, resulta revelador el origen de los dos primeros decanos comisarios (figura que con su nombre indica que eran nombrados por el ministerio/rectorado): Adolfo Muñoz Alonso, catedrático de Filosofía y antiguo falangista (UCM) y Víctor Reina catedrático de Derecho canónico, formado en la Universidad de Navarra (UNAV). Todos los primeros funcionarios destinados a las facultades de Ciencias de la Información de Madrid y Barcelona provienen de Humanidades o Derecho y establecen un territorio que conecta a los estudios de comunicación con las Humanidades.

Tabla 1. Directrices que han de seguir los planes de estudio de las facultades de Ciencias de la Información (España, 1974)

\begin{tabular}{|l|l|}
\hline Primer ciclo & Segundo ciclo \\
Obligatorias para todos los alumnos: & Obligatorias: \\
-Derecho de la Información & Sección de Periodismo \\
-Derecho Constitucional & -Empresa Informativa \\
-Geografía Humana & -Ética y Deontología \\
-Historia Universal (Introducción, Moderna y Contemporánea) & -Historia del Periodismo \\
-Historia Moderna y Contemporánea de España & -Periodismo Especializado \\
-Historia de los Sistemas Filosóficos & -Relaciones Internacionales \\
-Lengua Española & -Tecnología de la Información \\
-Literatura Española & -Teoría de la Comunicación \\
-Literatura Universal & -Teoría de la Opinión Pública \\
-Teoría General de la Información & Sección de Publicidad \\
Disciplinas diferenciales: & -Análisis y Control Publicitarios \\
Sección de Periodismo & -Creación Publicitaria \\
-Redacción (Análisis de las Formas de Expresión; Géneros Perio- & -Estadística \\
dísticos; Periodismo Interpretativo) & -Lenguaje Publicitario \\
-Tecnología de la Información & -Mercadotecnia \\
Sección de Publicidad & -Psicología \\
-Economía & -Sociología \\
-Medios Publicitarios & -Sociología de la Publicidad \\
-Mercadotecnia & Sección de Ciencias de la Imagen Visual y Auditiva \\
-Teoría General de la Publicidad & -Dirección y Realización \\
Sección de Ciencias de la Imagen Visual y Auditiva & -Empresa Informativa \\
-Estética e Historia del Arte & -Ética General y Profesional \\
-Formas de Expresión Audiovisuales & -Historia del Cine \\
-Teoría de la Imagen & -Teoría de la Programación \\
-Teoría de la Realización & -Teoría y Técnica de la Producción \\
& -Teoría y Técnica de la Realización \\
\hline
\end{tabular}

Es muy visible en el primer ciclo, común a todos los estudios, donde se encuentran asignaturas de Historia, Literatura, Lengua o Filosofía. En el segundo ciclo, ya específico para cada rama, encontramos asignaturas de Ciencias Sociales, sobre todo en Publicidad, alguna en Periodismo y ninguna en Ciencias de la Imagen visual y auditiva (la actual Comunicación Audiovisual). La única disciplina que posee el rubro de Comunicación, Teoría de la Comunicación, aparece exclusivamente en la rama de Periodismo.

Outsiders del poder universitario como el ya mencionado Vidal-Beneyto buscaron incidir en lo que estaba naciendo. Su opúsculo, Las ciencias de la Comunicación en la universidad española es publicado en el primer trimestre del curso académico en el que comienzan las clases de Madrid y Barcelona. Vidal-Beneyto utiliza sus contactos políticos para, ya en democracia, trabajar por el concepto de "comunicación", distinto del de "información". En el plan de estudios que propone establece como materias obligatorias un cuadro muy distinto al aprobado. En concreto, para el primer ciclo debía incluir Sociología, Economía, Ciencia política, Estadística, Psicología, y una disciplina proveniente de Teoría y análisis de la opinión pública (Vidal-Beneyto, 1972, p. 50). No conseguirá convencer a casi nadie, ni en esos años del tardofranquismo ni tampoco en el período democrático de la transición.

Se puede continuar atendiendo a los primeros profesores de las recién creadas facultades. Entre los que fueron catedráticos en la década de los setenta encontramos a Ángel Benito, proveniente de la Universidad de Navarra, que será el primer catedrático de periodismo en España (1976) y primer decano democrático de la Facultad de Ciencias de la Información de la Universidad Complutense de Madrid. Dígase, asimismo, que su actividad fue decisiva en el desarrollo de los combates ideológicos y epistemológicos en la década de los ochenta al imponer sus puntos de vista en el campo de periodismo, estableciendo el cambio de la denominación de la Teoría General de la Información frente a la de Teoría de la Comunicación. El segundo catedrático de periodismo (1976) es el profesor Martínez Albertos, también procedente de la Universidad de Navarra. Otros catedráticos del primer claustro de profesores fueron Alfonso Nieto Tamargo (catedrático de Empresa Informativa, y ex rector de la Universidad de Navarra) y José María Desantes Guanter (primer catedrático de Derecho de la información y Deontología ética informativa en 1979 y doctorado en la Universidad de Navarra). También fueron catedráticos Pedro Orive o Manuel Martín Serrano, el único caso de profesor relacionado con la Comunicación 
social que fue catedrático de Sociología, pero adscrito a Ciencias de la Información. En Ciencias de la Imagen, el primer catedrático sería Antonio Lara García y en Publicidad, José Ramón Sánchez Guzmán.

En las galeras, los profesores no numerarios (PNN) de Ciencias de la Información de Madrid, empezaron a hablar en las aulas de semiótica, de lingüística, de receptores, pero sobre todo pusieron en marcha la primera colección de libros española relacionada con la Comunicación: Cuadernos de la Comunicación. Su edición fue iniciada en 1976 por el publicista y psicólogo Pablo del Río. Entre sus volúmenes localizamos a los autores que pueden ser considerados las primeras aportaciones españolas al campo teórico de la comunicación: Santiago Montes, Gonzalo Abril, Pablo del Río, Manuel Martí Serrano, Javier del Rey Morato, Vicente Romano y Felicísimo Valbuena. Anteriormente, desde 1972 se encontraba en los quioscos la revista Comunicación XXI, una publicación amalgama de teorías de la comunicación, publicidad y cine dirigida también por Pablo del Río junto a Judy Good, y que se convirtió inmediatamente en punto de referencia de alumnos y profesores de Ciencias de la Información, capaz de articular el primer mapa cognitivo del campo. El editorial del primer número podía haber sido escrito, como fue, en 1972 o medio siglo más tarde:

“Comunicación XXI es fruto de nuestro tiempo. Es el siglo XX el que se ha presentado a la comunicación como nueva clave de las relaciones sociales y el que ha hecho posible que todos los conocimientos que tienen que ver con ella se vayan estructurando en una ciencia única" (Comunicación XXI, 1972, p. 3).

Muy poco después, a primeros de los años ochenta, Miquel de Moragas ensancha enormemente el mapa cognitivo del campo de la comunicación, tanto con sus trabajos de semiótica y comunicación de masas, como con las antologías de textos de sociología de la comunicación de la editorial Gustavo Gili.

Cuando llegaron las primeras elecciones democráticas, tanto Ángel Benito en Madrid (1981) como Miquel de Moragas en Barcelona (1982) abren un nuevo capítulo de la historia de la Comunicación, protagonizado por la creación de las áreas de conocimiento.

\section{Las áreas de conocimiento. Los idóneos.}

En 1984 aparece el inicial catálogo de áreas de conocimiento del que se habla en la Ley de Reforma Universitaria (LRU), primera norma de su rango en período democrático sobre la universidad. El objetivo de dichas áreas es regular las oposiciones a los cuerpos de funcionarios universitarios. En otras palabras, las áreas no se relacionan con la investigación, sino tan sólo con la ordenación docente al vincular a todo funcionario a unas determinadas asignaturas. Y dice la norma:

"se entenderá por área de conocimiento aquellos campos del saber caracterizados por la homogeneidad de su objeto de conocimiento, una común tradición histórica y la existencia de comunidades de investigadores nacionales o internacionales" (España, 1983, Art. 2.2).

Para constituirse como área de conocimiento se precisaba la presencia de cinco catedráticos. En el Real decreto 1888/1984 que desarrolla este aspecto se establecen, por primera vez, las dos áreas de conocimiento: Periodismo y Comunicación Audiovisual y Publicidad (España, 1984). A mediados de los años noventa hubo un intento muy serio de dividir en dos áreas las disciplinas de Comunicación Audiovisual y Publicidad. Huelga decir que no alcanzó el objetivo buscado. Nunca nadie ha buscado la creación de un área de conocimiento de Comunicación, como existe, por ejemplo, en Francia.

También en estos años se fijan los títulos de disciplinas académicas a impartir -lo que en tiempo se llamó asignaturas obligatorias-, lo que parcelaba por ley las materias de investigación de la Comunicación en territorios anejos, pero claramente diferenciados. La existencia de las áreas conlleva que la denominada 'comunicación' prácticamente desaparezca en los planos cognitivo y social en buena parte de los años ochenta. Entre otras cosas porque en la taxonomía de las áreas de comunicación en sociología aparecen las asignaturas de Teoría de la Comunicación y Teoría de la Comunicación Social a impartir en las facultades de Ciencias de la Información (que no en las de Sociología) por profesores de Sociología y no de Periodismo o Comunicación Audiovisual y Publicidad.

Como hemos dicho, la Teoría de la Información, diseñada por Ángel Benito como prolongación de una teoría general de periodismo, se impone como central en el desarrollo de los estudios de Periodismo. En Comunicación Audiovisual, con frecuencia se busca la legitimación en la incidencia social y en la investigación aplicada a la luz de lo que en aquellos años se llamaban nuevas tecnologías.

Pero lo sustantivo de la década de 1980 es la diferenciación creada por las áreas. Las pruebas de los llamados profesores idóneos acaecidas a lo largo de 1984, para ajustarse a la nueva ley democrática de la $L R U$, se revelan decisivas. Los idóneos cambiaron el perfil del sistema universitario español. Fueron concebidos para "facilitar" el acceso al funcionariado de profesores preparados y con una cierta antigüedad en la docencia. De una tacada, el área de periodismo se encontró con treinta funcionarios nuevos. En Comunicación Audiovisual y Publicidad fueron únicamente seis ${ }^{1}$. En suma, se crearon unas profundas bases topográficas para los estudios de periodismo.

\section{Los inicios de la cultura de la evaluación}

El mapa cognitivo y social de la comunicación en el sistema universitario español estaba agonizando cuando comenzó la cultura de la evaluación. El ajuste entre la estructura administrativa y las llamadas áreas de conocimiento lo había dejado maltrecho, sin publicaciones o revistas. 
En este sentido, incidimos de nuevo en que la Comunicación no figura en ninguna de las categorías clasificadoras de materias en investigación, tal como ocurre, por ejemplo, a la hora de solicitar los planes nacionales al Ministerio o de inscribir las tesis doctorales en plataformas como Teseo, del Ministerio de Educación. Lo mismo sucede en la taxonomía internacional establecida por la Unesco².

En este marco tampoco sorprende que, en la primera convocatoria de los sexenios de investigación, en el Campo 7 la mesa recoge en su título: “Ciencias sociales, políticas del comportamiento y de la educación". Debería investigarse la historia vital y las publicaciones de los profesores de las carreras de las facultades de Ciencias de la Información que decidieron mayoritariamente presentarse para ser juzgados mejor por sociólogos o educadores. Los primeros profesores de Comunicación que participaron como miembros de las comisiones fueron Mariano Cebrián y Jorge Lozano, y ninguno de ellos tenía que ver con los criterios de evaluación hegemónicos en Sociología o Educación. También conocemos que el 23 de febrero de 1993 la Facultat de Ciències de la Informació de la Universitat Autònoma de Barcelona es autorizada, tras la implantación de los estudios de Comunicación Audiovisual, a cambiar el nombre por el de Facultat de Ciències de la Comunicació (Generalitat de Catalunya, 1993). Como es sabido, por esa espita abierta entraron la gran mayoría de las facultades de España, excepción hecha de la más grande de todas ellas.

En otro sentido, el Libro blanco de los estudios de Comunicación (Aneca, 2005) es el primer documento oficial que recoge el vocablo 'comunicación'. El documento carece de cualquier valor legal3. Pero ciertamente el trabajo se financió con fondos públicos de la Aneca. Aunque no están disponibles las actas de las reuniones que permitirían observar el punto de vista de las universidades que abogaban por grados de tres años, lo cierto es que su lectura produce algún escalofrío descorazonador. Porque cuando en la información de la valoración del proyecto, nominalmente la primera página, se encuentra una falta de ortografía -“Se hecha [sic] de menos" (Aneca, 2005, p. 13.)- y lo firma, entre otros el catedrático de metafísica y luego Ministro de Educación, el profesor Ángel Gabilondo, sólo se puede concluir que los estudios de Comunicación no importan, digamos, mucho.

El corolario que se extrae de la lectura de El libro blanco conecta con la propia historia de los estudios. La Comunicación, en esencia, hace referencia no sólo a lo que podíamos definir como unas disciplinas de estudio vertebradas a partir de los procesos mediáticos sino, sobre todo, a la suma aditiva y por motivos científicamente no explicados de tres estudios (Periodismo, Comunicación Audiovisual, y Publicidad y Relaciones Públicas); y no cuatro, como ocurriría de haber contado con Documentación (que hoy suele acompañarse de la denominación "Información"; o dos, si se hubiera prescincidido de Comunicación Audiovisual. Ejemplos que podrían haberse dado, pues la cosmovisión del área de Periodismo se va a trasladar a todo el campo de estudios apropiándose de la totalidad de la Comunicación. Al menos eso debe concluirse si se atiende a que la coordinación general del proyecto estuvo llevada por tres profesores de Periodismo (Marcial Murciano -UAB-, Javier Davara -UCM- y Xosé López -USC-) y uno de Literatura (Miguel Nieto -US-).

\section{Capital simbólico de los estudios de Comunicación. Doctorados Honoris Causa}

En este punto en el que hemos observado la evolución de la creación del campo de la Comunicación en la universidad española y su vertebración a través de la creación de facultades y del acceso y posterior evaluación de su profesorado, podemos advertir que la Comunicación posee una precaria existencia social ligada a la docencia de los estudios de las ramas iniciales, que contemporáneamente conocemos como Periodismo, Comunicación Audiovisual y Publicidad. Por otra parte, el éxito de esas carreras ha tenido como efecto el crecimiento exponencial del número de estudiantes matriculados y, en consecuencia, del número de profesores encargados de la docencia. Estos, a su vez inmersos en la nueva cultura de la evaluación, han multiplicado sus publicaciones. Y su presencia mayúscula ha obligado, a su vez, a la incorporación a las comisiones de evaluación de un número cada vez más elevado de funcionarios adscritos a las áreas de Periodismo, Comunicación Audiovisual y Publicidad. Sin embargo, sigue sin abordarse la "existencia teórica" de los estudios de Comunicación, y por ello la disciplina sigue necesitada de legitimación. Cabe pensar que su capital simbólico en la universidad no ha crecido en las dos últimas décadas. Conviene ahora recordar una de las muchas intervenciones de Pierre Bourdieu sobre la noción de capital simbólico:

"El grado de autonomía del campo (y, con ello, el estado de las relaciones de fuerzas que en él se instauran) varía considerablemente según las épocas y las tradiciones nacionales. Depende del capital simbólico que se ha ido acumulando a lo largo del tiempo" (Bourdieu, 1995, p. 327).

Afirmamos que los estudios de comunicación no conseguirán jamás su capital simbólico en los recintos universitarios por las citas de sus investigadores en las revistas de los $J C R$, sino por otros factores sociales. Como colofón final a nuestro repaso histórico, intentaremos iluminar este tema observando los doctorados Honoris Causa propuestos por las facultades de Ciencias de la Información / Comunicación. Como se sabe, la concesión de un doctorado Honoris Causa por una universidad es una decisión de un rector avalada por un acuerdo del Consejo de gobierno y presentado las más de las veces tras pasar por una Junta de facultad del centro que lo propone. Es decir, obliga a un trabajo de consensuar intereses variados para conseguir el apoyo de sensibilidades diversas. Se da la circunstancia de que los estudios de Comunicación, en esencia sus profesionales, pueden dar capital simbólico a la universidad que los concede, aunque el galardón no haya sido una proposición emanada por las facultades que imparten las enseñanzas de comunicación.

El perfil genérico de doctor Honoris Causa de Comunicación en España es el de un profesional de alguna de las ramas de los medios de comunicación, de origen español frente al internacional, y varón 
Así, podemos establecer un primer listado (tabla 2) de personas más premiadas con doctorados Honoris Causa que pueden provenir de oficios relacionados con los medios de comunicación o del pensamiento científico de las áreas de Comunicación.

Tabla 2. Doctores Honoris Causa relacionados con las ciencias de la Comunicación con más de dos nombramientos (1972-2019) ${ }^{4}$

\begin{tabular}{|c|l|l|}
\hline Veces nombrado Honoris Causa & \multicolumn{1}{|c|}{ Doctor Honoris Causa } & \multicolumn{1}{|c|}{ Universidades } \\
\hline 9 & Mario Vargas Llosa & UA; UBU; UC3M; UCLM; UE; UGR; UM; UMA; UR \\
\hline 5 & Iñaki Gabilondo & UBU; UdL; URJC; UV; US \\
\hline \multirow{2}{*}{4} & Miguel Delibes & UAH; UC; USAL; UVa \\
\cline { 2 - 3 } & Manuel Castells & UAB; UCLM; ULE; UV \\
\hline \multirow{2}{*}{3} & Francisco Ayala & UCM; UGR; US \\
\cline { 2 - 3 } & Luis García Berlanga & UCM; UMH; UPV \\
\cline { 2 - 3 } & Rosa María Calaf & UJ; UMH; URV \\
\hline \multirow{2}{*}{2} & Umberto Eco & UBU; US \\
\hline \multirow{2}{*}{2} & Joaquim Maria Puyal & UAB; URV \\
\cline { 2 - 3 } & Carlos Saura & UCM; Unizar \\
\cline { 2 - 4 } & Armand y Michèle Mattelart & UMA; UVa \\
\hline & Antonio Mingote & UAH; URJC \\
\hline
\end{tabular}

Como puede observarse, un listado de este tipo invita a pensar en los motivos por los que unas y otras universidades deciden otorgar su máximo reconocimiento. Parece evidente la fuerza que posee el 'terruño' en los Honoris: el sociólogo albaceteño Manuel Castells o el cineasta manchego Pedro Almodóvar (ambos por la UCLM); el salmantino Basilio Martín Patino por la USAL; Carlos Saura, aragonés, por la de Zaragoza; Antonio Banderas, procedente de Málaga, por la UMA. Otros se encaminan a algo así como una política de marketing de la universidad, que no parece suponga ningún beneficio a los estudios de Comunicación: la Universitat Miguel Hernández d'Elx concedió el doctorado Honoris Causa al cineasta Luis García Berlanga el mismo mes en que iniciaba los estudios de Comunicación Audiovisual. Y luego están las personalidades que, aunque innegablemente poseen una apreciable actividad en el periodismo, son reconocidos socialmente por otra actividad. Desde luego es el caso de los escritores Vargas Llosa, Miguel Delibes, Francisco Ayala o Manuel Vázquez Montalbán.

Observemos los Doctores Honoris Causa propuestos por facultades en cuya denominación aparece en exclusiva la palabra Ciencias de la Comunicación/Información. Son nueve universidades:

- Facultad de Ciencias de la Información (UCM, creada en 1972)

- Facultat de Ciències de la Comunicació (UAB, 1972)

- Facultad de Comunicación (UNAV, 1972)

- Facultad de Comunicación (UPSA, 1988)

- Facultat de Comunicació (UPF, 1990)

- Facultad de Ciencias da Comunicación (USC, 1990)

- Facultad de Ciencias de la Comunicación (UM, 1992)

- Facultad de Comunicación (US, 1995)

- Facultad de Ciencias de la Comunicación (URJC, 2000)

Se pueden dividir estas facultades en dos grupos en relación con la disponibilidad oficial de los datos:

- el primero lo integran las siete cuya información se encuentra públicamente disponible (UCM, UAB, UPF, UNAV, USC, UMA y US) y constituirán nuestra muestra principal';

- el segundo grupo comprende la UPSA y la URJC, que no cuenta con los listados de doctores Honoris Causa públicos y, en consecuencia, reducen a lo infinitesimal el valor de su capital simbólico ${ }^{6}$.

Las siete facultades del primer grupo han nombrado en las últimas cinco décadas un total de 25 doctores Honoris Causa. La tabla 3 recoge, por orden cronológico, los nombramientos de cada una de estas facultades y se detalla la ocupación principal de los homenajeados en las categorías de Académicos, Periodistas, Profesionales de la industria del cine (cineastas y actores), Profesionales de la industria publicitaria, Fotógrafos, Músicos y Políticos.

Del listado anterior se observa que no existe una relación directa entre la historia de las facultades y el número de doctorados Honoris Causa otorgados. En otras palabras, cada universidad puede buscar la acumulación de capital simbólico por sendas distintas. Sirva la siguiente disparidad como ejemplo: la Facultad de Ciencias de la Información de la UCM ha otorgado el mayor número de doctores Honoris Causa (once en total), mientras que otra facultad creada el mismo año 1972, la de Facultad de Comunicación de la UNAV, solo ha proclamado uno.

No resulta sencillo elaborar una reflexión concluyente sobre el perfil del homenajeado por las facultades de Comunicación en España. Los listados nos remiten a estrategias variadas y que cabría analizar en cada universidad de manera independiente. Pero dado que, retomando de nuevo a Bourdieu, la creación de capital simbólico se deposita en el trans- 
Tabla 3. Doctores Honoris Causa propuestos por facultades dedicadas en exclusiva a las ciencias de la comunicación y ocupación principal. Entre paréntesis, fecha de creación de la facultad. Fuente: UCM, UAB, UNAV, UPF, USC, UMA, US.

\begin{tabular}{|l|l|}
\hline \multicolumn{2}{|l|}{ Facultad de Ciencias de Ia Información, UCM (1972) } \\
\hline Andrés Segovia Torres, 1987 & Músico \\
\hline Miguel Delibes, 1987 & Escritor / Periodista \\
\hline Eulalio Ferrer Rodríguez, 1989 & Industria publicidad \\
\hline Luis García Berlanga, 1989 & Cineasta \\
\hline Abel Matutes Juan, 1992 & Político \\
\hline Luis Alberto Lacalle Herrera, 1992 & Político \\
\hline Giovanni Spadolini, 1993 & Político \\
\hline Edward Osborne Wilson, 1995 & Académico \\
\hline Francisco Umbral, 1999 & Escritor / Periodista \\
\hline Carlos Saura, 2014 & Cineasta \\
\hline Constantin Gavras, 2016 & Cineasta \\
\hline & \\
\hline Facultat de Ciències de Ia Comunicació, UAB (1972) \\
\hline Manuel Vázquez Montalbán, 1997 & Escritor / Periodista \\
\hline Pere Portabella, 2008 & Cineasta \\
\hline Isabel Steva Hernández “Colita”, 2012 & Fotógrafa \\
\hline Manuel Castells, 2017 & Académico \\
\hline Joaquim-Maria Puyal, 2019 & Periodista \\
\hline
\end{tabular}

\begin{tabular}{|l|l|}
\hline \multicolumn{2}{|l|}{ Facultad de Ciencias de la Comunicación, UNAV (1972) } \\
\hline Robert Picard, 2019 & Académico \\
\hline \multicolumn{2}{|l|}{ Facultat de Comunicació, UPF (1990) } \\
\hline Woody Allen, 2007 & Cineasta \\
\hline Joan Manuel Serrat, 2011 & Músico \\
\hline Frederick Wiseman, 2016 & Cineasta \\
\hline \multicolumn{2}{|l|}{} \\
\hline Facultade de Ciencias da Comunicación, USC (1990) \\
\hline Ignacio Ramonet, 2003 & Periodista \\
\hline \multicolumn{2}{|l|}{} \\
\hline Facultad de Ciencias de la Comunicación, UMA (1992) \\
\hline Antonio Banderas, 2010 & Actor \\
\hline Armand y Michèle Matterlart, 2014 & Académicos \\
\hline \multicolumn{2}{|l}{} \\
\hline Facultad de Comunicación, US (1995) \\
\hline Francisco Ayala, 1994 & Escritor/Periodista \\
\hline Umberto Eco, 2010 & Académico \\
\hline
\end{tabular}

curso del tiempo, puede servirnos para llegar a conclusiones observar los nombramientos realizados por la Facultad de Ciencias de la Información de la UCM, por ser una de las veteranas y, a su vez, la que más doctorados Honoris Causa ha propuesto, habiendo procedido de ella un $44 \%$ de los nombramientos analizados en el caso de facultades dedicados en exclusiva a las Ciencias de la Comunicación (tabla 2).

Hagamos una primera división entre perfiles profesionales y académicos (gráfico 1). Encontramos que en un porcentaje muy elevado los doctores Honoris Causa pertenecen al primer grupo. En el caso de la UCM, por cada académico, la Facultad de Ciencias de la Comunicación nombró 10 profesionales de los medios de comunicación. En otras facultades esta dinámica se mantiene: en la $U A B$, sólo uno de cada cinco doctores Honoris Causa es académico, y no existe ninguno en la UPF o en la USC. Casos de muy reducida representatividad en datos globales como la UNAV, UMA o US permiten hablar de proporciones mayores de académicos: la de Navarra cuenta con un académico como su único Honoris Causa y las dos universidades andaluzas nombraron por igual un perfil profesional y uno académico. La conclusión provisional es contundente: los profesores de comunicación, que a la postre son los que a través de las facultades eligen la adjudicación de doctorados Honoris Causa, no consideran que puedan conseguir prestigio y capital cultural entre sus pares académicos, sino por profesionales. Es imposible saberlo, pero parece que, si el objetivo fuese el reconocimiento de los compañeros universitarios, la estrategia puede estar equivocada. Porque el otro punto de vista para abordar el tema es más demoledor: alardeamos entre nosotros sobre la cualidad de la cientificidad de nuestro trabajo y cuando queremos mostrarnos públicamente en nuestras universidades no proponemos para doctorado Honoris Causa a nuestros académicos, sino a nuestros profesionales.

En el ejemplo de la UCM también parecen detectarse injerencias externas políticas en los doctorados Honoris Causa. Tampoco es para vanagloriarse. En los perfiles profesionales de los nombramientos de la UCM destacan los escritores que participan también en labores del periodismo (18\%), y los profesionales del cine (28\%). La publicidad en la UCM, dividida su alma entre las facultades de Comunicación y las variantes de los estudios de marketing, y como en general ocurre en todas las facultades, parece que no consigue ni el glamour social que poseen algunas profesionales de los medios o del cine ni tampoco el reconocimiento académico.

Si bien la UCM condensa la muestra más representativa de esta cuestión, en otras universidades se encuentran perfiles profesionales como fotógra-

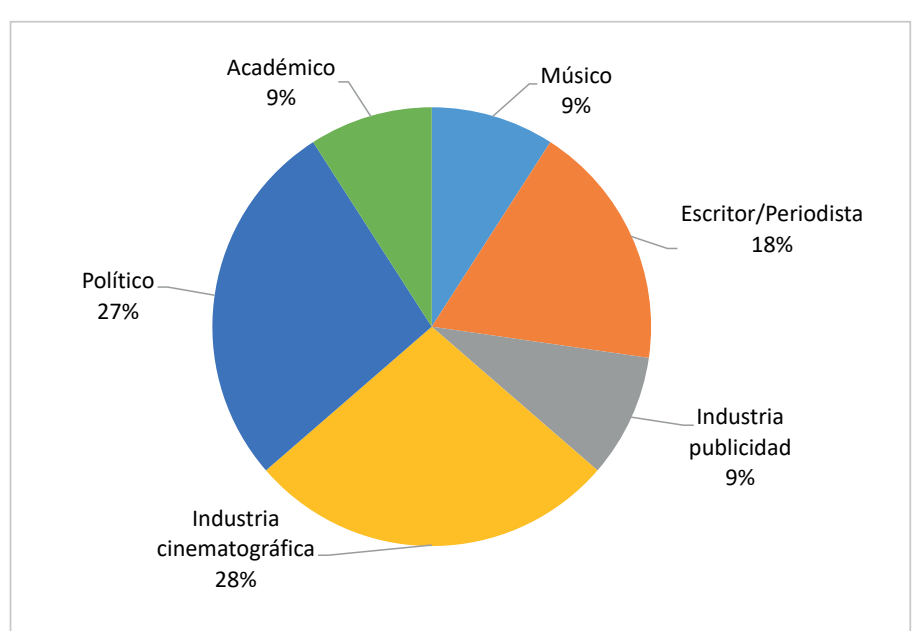

Gráfico 1. Perfiles profesionales de los doctores Honoris Causa nombrados por la Facultad de Ciencias de la Información de la UCM (1972-2019) 
fos, actores o dibujantes gráficos que se pueden añadir a las citadas como las profesiones homenajeadas por las facultades de Comunicación en España.

Por último, si además de su ocupación observamos la procedencia y el género de los premiados, se puede decir que el perfil genérico de Honoris Causa de comunicación en España es el de un profesional de alguna de las ramas de los medios de comunicación, de origen español frente al internacional y varón. La limitada y casi inexistente presencia de mujeres (apenas 3 en el corpus analizado compuesto por 25 honoris) arroja una de las conclusiones más escandalosas sobre el proceso de creación de capital simbólico. Facultades de Comunicación de universidades consolidadas como la UCM, UPF, USC, US y UNAV ni siquiera cuentan con un nombramiento de doctora Honoris Causa.

\section{Conclusión}

A lo largo de estas páginas se ha propuesto un marco general de hitos históricos en los distintos períodos de los estudios de Comunicación en España. La visión historiográfica nos permite evidenciar que algunas de las problemáticas actuales de la investigación en el campo de la Comunicación y sobre las que se solicita una mayor atención y reflexión -pues no resulta ser otro la llamada de este número de Profesional de la información-se constituyeron ya en el origen del asentamiento de las bases de la Comunicación como disciplina científica y universitaria, atributos que van de la mano. Desde la indefinición de la disciplina, bien sea en el seno de otras o frente a ellas, hasta la heterogeneidad de las vías de legitimación mediante la creación de capital simbólico, observamos que queda camino por recorrer en la reflexión colectiva. Este y el de otros compañeros no es nada más que el intento por hacer un primer desbroce de la vegetación de un bosque todavía frondoso, como es la historia de los estudios de Comunicación en España.

\section{Notas}

1. Aunque prolija, merece la pena desplegar la lista de los idóneos:

- Periodismo: César Aguilera, Enrique Aguinaga, Magdalena Albero, Porfirio Barroso, Eugenio Barrio, Javier Davara, María del Rosario De Mateo, Javier Del Rey, Bernardo Díaz Nosty, Pedro Farías, Carmelo Garatonondía, Josep Griffreu, Juan Gutiérrez, Eduardo Javier Mariñas, José Antonio Martín Aguado, Tomás Martín, César Molinero, Manuel Parés; Javier María Pascual, Miguel Pérez Calderón, José Manuel Pérez Tornero, José Julio Perlado, Alejandro Pizarroso, Andrés Romero, María Dolores Sainz, Luisa Santamaría, Petra Secanella, Marcelino Tobajas, Iván Tubau, Lorenzo Vilchez y Hortensia Viñes - Comunicación Audiovisual y Publicidad: Francisco Carrera, Mario Herreros, Emili Prado, Ramón Roselló, Luis Solano, Enrique Torán, Justo Villafañe.

2. Hace veinte años, a mediados de los noventa, el catedrático Francisco García dirigió una campaña entre los profesores para conseguir la inclusión de la Comunicación en los códigos Unesco. No lo consiguió (García-García, 2007).

3. Una reveladora anécdota local. En la Universidad en la que trabajan los dos firmantes de este artículo, las autoridades académicas establecieron que los libros blancos no tenían ninguna utilidad práctica y en consecuencia no deberían utilizarse para ninguna propuesta de grados nuevos.

4. Para facilitar la lectura, desde este punto se opta por la utilización de las siglas de las universidades analizadas y se detallan a continuación sus denominaciones completas (por orden alfabético):

- Universidad Carlos III de Madrid (UC3M)

- Universidad Complutense de Madrid (UCM)

- Universidad de Alcalá de Henares (UAH)

- Universidad de Burgos (UBU)

- Universidad de Castilla la Mancha (UCLM)

- Universidad de Extremadura (UEX)

- Universidad de Granada (UGR)

- Universidad de La Rioja (UR)

- Universidad de León (ULE)

- Universidad de Málaga (UMA)

- Universidad de Murcia (UM)

- Universidad de Navarra (UNAV)

- Universidad de Salamanca (USAL)

- Universidad de Sevilla (US)

- Universidad de Valladolid (UVa)

- Universidad de Zaragoza (Unizar)

- Universidad del País Vasco/Euskal Herriko Unibertsitatea (UPV/EHU)

- Universidad Europea de Madrid (UE)

- Universidad Rey Juan Carlos (URJC) 
- Universidade de Santiago de Compostela (USC)

- Universitat Autònoma de Barcelona (UAB)

- Universitat d'Alacant (UA)

- Universitat de Lleida (UdL)

- Universitat de València (UV)

- Universitat Jaume I (UJI)

- Universitat Miguel Hernández d'Elx (UMH)

- Universitat Politècnica de València (UPV)

- Universitat Pompeu Fabra (UPF)

- Universitat Rovira i Virgili (URV)

5. La fuente primaria de los datos que ofrecemos proviene de los repositorios institucionales de las propias universidades.

6. Fuera del marco y como dato complementario podemos decir que hemos observado que la Universidad Rey Juan Carlos ha sido muy prolífica en la concesión de Honoris Causa. Su política parece claramente orientada hacia los profesionales de la prensa como los periodistas Iñaki Gabilondo (2007); Luis del Olmo (2007); Luis María Ansón (2015); Juan Luis Cebrián (2015); Luis Fernández (2017) y Victoria Prego (2018), además de al dibujante gráfico Antonio Mingote (2007).

\section{Referencias}

Aneca (2005). Libro blanco de los títulos de Grado en Comunicación. Madrid: Agencia Nacional de Evaluación de la Calidad y Acreditación.

http://www.aneca.es/var/media/150336/libroblanco_comunicacion_def.pdf

Bourdieu, Pierre (1995). Las reglas del arte: génesis y estructura del campo literario. Barcelona: Anagrama. ISBN: 978 8433913975

Clemente-Mediavilla, Jorge; Ramírez-Alvarado, María-del-Mar (coords.) (2020). “Docencia e investigación en Comunicación en España". Observatorio ATIC n. 3. Salamanca: Comunicación Social. ISBN: 9788417600297

Comunicación XXI (1972). “Editorial”. Comunicación XXI, mayo, n. 1, p. 3.

España (1970). “Ley 14/1970, de 4 de agosto, general de educación y financiamiento de la reforma educativa”. BOE, n. 187, 6 agosto.

https://www.boe.es/buscar/doc.php?id=BOE-A-1970-852

España (1971). “Decreto 2070/1971, de 13 de agosto, por el que se regulan los estudios de periodismo y demás medios de comunicación social en la universidad". BOE, n. 220, 14 septiembre.

https://www.boe.es/buscar/doc.php?id=BOE-A-1971-1180

España (1974). "Resolución por la que se determinan las directrices que han de seguir los planes de estudio de las facultades de ciencias de la información". BOE, n. 14, 16 enero.

https://www.boe.es/boe/dias/1974/01/16

España (1983) “Ley orgánica 11/1983, de 25 de agosto, de reforma universitaria”. BOE, n. 209, 1 septiembre. https://www.boe.es/buscar/doc.php?id=BOE-A-1983-23432

España (1984). “Real decreto 1888/1984, de 26 de septiembre, por el que se regulan los concursos para la provisión de plazas de los cuerpos docentes universitarios". BOE, n. 257, 26 octubre.

https://www.boe.es/buscar/doc.php?id=BOE-A-1984-24014

García-García, Francisco (2007). “Los medios de comunicación y los códigos de la Unesco”. Icono14, v. 5, n. 1, pp. $384-396$. https://doi.org/10.7195/ri14.v5i1.383

Generalitat de Catalunya (1993) “Decreto 71/1993, de 23 de febrero, por el que se autoriza el cambio de nombre de la Facultad de Ciencias de la Información de la Universidad Autónoma de Barcelona por el de Facultad de Ciencias de la Comunicación y se implantan los estudios conducentes a la obtención de los títulos de licenciado en Comunicación Audiovisual, licenciado en periodismo y licenciado en publicidad y relaciones públicas". DOGC, n. 1723,19 marzo. https://portaldogc.gencat.cat/utilsEADOP/AppJava/PdfProviderServlet?document/d=73676\&type=01\&language=es_ES

Goyanes, Manuel (2017). Desafío a la investigación estándar en comunicación. Colección EPI Scholar. Barcelona: UOC. ISBN: 9788491166757

Rodríguez-Serrano, Aarón; Gil-Soldevilla, Samuel (2018). Investigar en la era neoliberal. Visiones sobre la investigación en Comunicación en España. Bellaterra (Barcelona): Universitat Autònoma de Barcelona. ISBN: 9788449080401

Sierra-Caballero, Francisco; Alberich-Pascual, Jordi (eds.) (2019). Epistemología de la comunicación y cultura digital: retos emergentes. Granada: Universidad de Granada-AEIC. ISBN: 9788433865274

Vidal-Beneyto, José (1972). Las ciencias de la comunicación en la universidad española. Bilbao: Zero. ISBN: 8431701560 